\title{
25 Research Suare \\ The Model and Strategic Design of Taoist Chinese Temples Built in the 19th Century in Klang Valley, Malaysia
}

\section{YM Yeong}

Universiti Putra Malaysia

Nangkula Utaberta ( $\sim$ nangkula@uthm.edu.my )

Assoc. Prof Dr. Nangkula Utaberta, Department of Architecture, Faculty of Civil Engineering and Built Environment, Universiti Tun Hussein Onn Malaysia (UTHM) https://orcid.org/0000-0003-1500-8753

Nor Atiah Ismail ismail

Universiti Putra Malaysia

Khairul aidil Abd Rahman

Universiti Putra Malaysia

Research article

Keywords: Strategic Design, Taoist Chinese temple, Quadrangle, Architecture, Feng Shui

Posted Date: December 31st, 2020

DOI: https://doi.org/10.21203/rs.3.rs-136155/v1

License: (c) (i) This work is licensed under a Creative Commons Attribution 4.0 International License. Read Full License 


\section{Abstract}

Chinese Taoist temples feature distinctive architecture styles which signify Chinese descendants. Majority of these authentic designs are inherited and imitated from ancient China c. 1600221 BC ( the Shang dynasty (ㅁ) C.1600-1046 BCE and Zhou dynasty (ㄷ) 1046-256 BC), particularly with regard to Geomancy or feng shui (미). This paper aimed to investigate the design typology, model, and strategic design of Chinese Taoist temples constructed in the 19th century in Malaysia. Ten temples were selected for analysis, and these samples were assessed qualitatively under consolidation of building model for analyzation. Results revealed that none of the buildings formed a quadrangle; instead, these building models were merely strategized in either a rectangular or a square shape. This could be due to the topological features and scales of the buildings. The results also showed that all the sample buildings attempted to compromise the theory of quadrangle, which is a good mechanism for air ventilation. Only half of the sample buildings achieved the scientific theory of 'efficient pollutant clearance' for maintaining air quality within the interior of the buildings as the remaining $50 \%$ of the building samples did not have a water outlet built within the parameter of their courtyards. The findings suggest that the owners of these buildings may not have an in-depth understanding of the principle of 'quadrangle'. Therefore, the author suggests that a model of design typology must be clearly formulated in order to conceptualize a better interior environment for Chinese Taoist temples.

\section{Introduction}

The architecture of Chinese Taoist temples distinctively reflects the Chinese culture and its historical value throughout various civilisations. Archaeological evidence revealed that most of the strategic designs of these Chinese Taoist temples were inherited from ancient China c. 1600-221 BC, in particular, from the Shang dynasty (마) C.1600-1046 BCE and Zhou dynasty (미)1046-256 BCE (Williams, 1941). The remains unearthed at Zhouyuan site which allowed the analyses of the foundation of a palace, temples, and mansions of noble families, demonstrated efficient architectural designs and space configurations (Jinpeng, 2009). Traditionally, a temple is housed within a palace, known as 'ancestral temple', and in terms of structural design, both spaces were interrelated. A palace is an exceptional residential building provided to the ruler of a political administration, while a temple is a place where official religious rituals are held. Henceforth, the structural arrangement and space configuration of these two spaces were found to be exclusive and exhilarated (Lip, 1995). The design strategy and construction process were complex as many factors had to be taken into consideration. Geomancy or "feng shui" (ㅁ), for instance, was one of the factors to be considered, and it has been adopted since ancient China (Chen, Feng, \& Wang, 1997). The philosophy of Geomancy refers to the practice of scientifically narrating the orientation and complementary forces of two elements i.e. wind and water in creating a harmonious environment to the occupants of the space (He, 1990; Chen, 1998), and with this theory, the strategy of 'quadrangle' building was specifically introduced. This principle was applied to ensure that the palace and the temple were built in a harmonious manner for the ruler to perform his specific duties. This paper assessed the strategic 
designs and investigated the topographical features of the Chinese Taoist temples built in the $19^{\text {th }}$ century in Malaysia.

\section{Literature Review}

The literature review provides a thorough discussion on the strategy or implication related to quadrangle buildings. 'Quadrangle' means having a courtyard within an enclosed room or building, and it helps make a building 'healthy' due to its optimal performance in providing good air quality and environment (Chen et al., 1997). Based on the literature review, two scenarios can be seen pertaining to the development of the Chinese Taoist temples. The first scenario is derived from the endless efforts of Chinese archaeologists who made the discovery and gained direct knowledge from the remains of building foundations built during ancient China which had a quadrangle design and various space configurations (Andersson, 1924; Jinpeng, 2009). However, due to limited resources for many related typical building materials, no identification of physical or comprehensive vertical architecture design for Taoist Chinese Temples was made. This could be possibly due to the fact that some components and materials have turned to ruins as they were built more than 3000 years ago, or it could be due to the fact that the existence of certain components during the ancient China is questionable. The second scenario shows that the knowledge was directly retrieved from both the physical and visual architectural data of the typical Chinese Taoist temple complexes that are still standing. The development of these temples reached its zenith during the Ming (AD 1368-1644) and Ching (AD 1644-1911) dynasties. The complexity and richness of the architectural designs, spatial planning, material application, ornamentals, and artefacts can be seen from the reputable surviving buildings in the Forbidden City of China, which were constructed dominantly in the model of quadrangle, square, rectangular, round, octagonal, and geometric (Lip, 1995).

\section{The Model and Strategic Design: The Influence of 'Quadrangle'}

The Chinese Taoist temples are a holy place for worshiping. Established specifically for praying sessions, they were designed with a pavilion, an offering area, a divine hall, a recital area, a reception area, a living room, and a garden; a design which reflects asceticism (Lip, 1995). Structurally, these temples were constructed with vertical solid timber structures which rested on earth platforms, erected with masonry wall, covered with roof tiles, and adorned with carpentry and stonework (Guo, 2000) in a quadrangle design. This quadrangle design implications have been commonly applied since the ancient times. In fact, the theory of 'quadrangle' is recognisable nationwide as an effective approach for the builtenvironment. Historically, researchers discovered that the quadrangle design was not solely from ancient China, but it had also been widely used in the western region for cloisters since the Carolingian dynasty ( $7^{\text {th }}$ century AD) (Boto Varela, 2017). In the perspective of geomancy or feng shui, literally, the wind and water elements are believed to help create harmony in the environment. The allocation for a courtyard, surrounded by other rooms, provides a better performance for cross ventilation. This reflects the 
successful creation of a symbiosis within a building (Su \& Tsai, 2013). A quadrangle building is designed with the following criteria (C): C1. minimises demolition of surrounding wall, C2.courtyard remains as a huge opening for air ventilation, and C3.water outlet is fully equipped within the courtyard to clear off pollutants (He, 1990). Chen (1998) emphasised that these conditions allow a building to naturally achieved the desired environment with positive outcomes i.e. (0): 01. the closed surrounding experiences less outside disturbances, 02 . natural sunlight, rain water, fresh air, and wavelength penetrating and circulating within the courtyard are maximized, 03. good temperature for spaces close to the courtyard is maintained. The picture and diagram below illustrate the strategy for effective air circulation within the building.

\section{Methodology}

The ten selected samples $(\mathrm{N}=10)$ within the Klang Valley, Malaysia which were built in the $19^{\text {th }}$ century, were qualitatively assessed based on the design typology of Chinese Taoist temples. The investigation focused on the topological features and design approach implemented in the samples. Two data collection methods were administrated: first, interview sessions, and secondly, consolidation of sketches and photography of the exterior and interior of the buildings. Interviewees were limited to the care takers or committee members of the temples, and they helped provide answers to other matters that were not depicted at each site. Finally, data gathered were analyzed systematically for visual comparison and classification.

\section{Findings \& Discussion}

\section{Earth Platform within the Taoist Chinese Temples}

Chinese Taoist temples built in the $19^{\text {th }}$ century in Malaysia are recognized as heritage buildings under the religious classification (Malaysian Government, 2006). The temples, located in both the town and rural areas, were basically constructed based two common models and on three different earth levels. An intercomparison on the three different earth levels showed that most $(70 \%[\mathrm{~N}=7])$ of these temples were built on a linear level; $20 \%(\mathrm{~N}=2)$ rested on an elevated platform; and only $10 \%(\mathrm{~N}=1)$ were built on a steep slope (see Figure 2). Surprisingly, this research also discovered that the quadrangle strategy was not widespread in Malaysia. This finding contradicts the findings of the research done by Evelyn (Lip, 1995) who claimed that the models of the Chinese Temples varied from quadrangle, square, rectangular, round, octagonal, and geometric (Lip, 1995) (see Figure 3). The findings of the current study showed an absence of a round, octagonal and geometric forms in the $19^{\text {th }}$ century temples built in Malaysia. Presumably, her research model should be part of the modern Architecture or the latest development where the design is in mature zenith.

\section{The Models of the Buildings: Rectangular and Square}


The two most common models found in the samples were rectangular, $80 \%(\mathrm{~N}=8)$ and square form, $20 \%$ $(\mathrm{N}=2)$ (see Figure 4 ) instead of quadrangle, and both were built in respond to the land formation and the surrounding features.

This phenomenon could be highly due to the topological features surrounding the temples and building scale itself. Zhouyuan palace (Jinpeng, 2009), cloister (Boto Varela, 2017), Forbidden City in China (Lip, 1995) are some of the examples of buildings built using the quadrangle model, and they were of a huge scale or involved the construction of multiple architecture complexes (see Figure 5, Image 1 \& Image 2) whereas the samples in Malaysia were of a small scale and all only involved a single architecture complex. In addition, 70\% ( $\mathrm{N}=7)$ of these samples were located in a town area, so the temples were surrounded by cluster of buildings or shop lots.

Regardless of the influence coming from the local context, the designing force and idea adoption seem to have been modified to compromise the quadrangle model; rectangular and square shapes are quite similar to quadrangle. This indicates that the owners of the temples were aware of the optimal performance of quadrangle and attempted to compromise with this theory even though they lacked land or space to house a huge courtyard within the temples.

\section{New Creation Introduced in the Architecture of the Buildings: Sky Windows}

Additionally, the results showed that $50 \%(\mathrm{~N}=5)$ of the samples adopted the idea of having a courtyard (see Figure 5 , Image 3 ) while the remaining $50 \%(\mathrm{~N}=5)$ of the samples were constructed with other architectural creations, which relected a modification that compromised the theory of a courtyard i.e. the use of a 'sky window' (see Figure 5, Image 4). This is not a common component in ancient China or Chinese Taoist temples built in Malaysia in the modern era, but it is a part of the dominant features that have existed in Taoist Chinese temples built in the $19^{\text {th }}$ century in Malaysia.

A sky window constructed with vertical supports covered the entire ceiling and roof tiles. It has a similar function as a courtyard in providing good air ventilation as it enables carbon emission caused by the burning of joysticks to be released efficiently. The author suggests that the adoption of this new idea is influenced by the local climate. Malaysia has a hot and humid climate, so a sky window plays a key role in creating a better shelter for the occupants of the space. The author also noticed that the 'window' has less architectural significance, and it is built only for decorative purposes (see Figure 6). Vertical bamboos lined within the opening solely portray an aesthetic appearance. Thus, further investigation is needed in order to consolidate a solid evidence and support the author's hypothesis

Undoubtedly, the existence of a sky window has fulfilled one of the quadrangle criteria cited by $\mathrm{He} \mathrm{(1990),}$ as specified in the literature review under criteria (C2). Nevertheless, the author was unable to identify if the sky window is able to achieve the scientific theory cited by Chen, i.e. "courtyards provide efficient pollutant clearance" (Chen et al., 1997) (see the diagram illustrated in Figure 1) due to the different characters: 'opening' for a courtyard and 'enclosed' for a sky window. In addition, the author also discovered that regardless of whether a temple is built with a courtyard or a sky window, $50 \%(\mathrm{~N}=5)$ of the 
temples did not fulfill another 'quadrangle criteria' under criteria (C3) since no water outlet is found within the parameter of the courtyard. As stated in Chen's theory, gas, which is lighter will float or dissipate upwards while pollutants, which are heavier, will sink to the ground, channeling out by the water to the sewer systematically (see diagram illustrated in Figure 1).

Thus, it can be concluded that even though $100 \%$ of the samples fulfilled the criteria of quadrangle (C2), i.e. being built strategically to provide a good mechanism for air ventilation, half of the samples did not achieve the scientific theory of "efficient pollutant clearance" to maintain quality air within the interior as they did not fulfill criteria (C3).

\section{Conclusion}

The theory of quadrangle has been applied nationwide, and it has been well developed based on the elements of the wind and water according to the feng shui perspective. This strategic design approach perfectly complements the surrounding nature to provide a harmonious and friendly environment for worshipping. In general, criteria (C1) is not applicable in the samples in Malaysia; most probably because the building samples were merely a simple complex and are small in scale. To achieve Chen's scientific theory, criteria of (C2) and (C3) must be fulfilled. The results indicate that owners of the temples are not aware of the scientific theory by Chen, so the author suggests that a design guideline must be clearly formulated in-order to conceptualize a better interior environment for Chinese Taoist temples.

\section{Declarations}

\section{Competing interests}

The authors declare that they have no known competing financial interests or personal relationships that could have appeared to influence the work reported in this paper.

\section{funding}

Not Applicable.

\section{References}

1. Andersson, J. G. (1924). Archaeology in China. The Antiquaries Journal, 4(2), 162. http://doi.org/10.1017/S0003581500091071

2. Boto Varela, G. (2017). Building Monastic Cloisters in the Iberian Peninsula ( $8^{\text {th }}-11^{\text {th }}$ centuries): Regular Layouts and Functional Organization. Hortus Artium Medievalium, 23(1), 222-239. http://doi.org/10.1484/J.HAM.5.113716

3. Chen, Q., Feng, Y., \& Wang, G. (1997). Healthy Buildings Have Existed in China Since Ancient Times. Indoor and Built Environment, 6(3), 179-187. http://doi.org/10.1177/1420326X9700600309 
4. Chen, V. F. (1998). The Encyclopedia of Malaysia: Architecture. Archipelago Press.

5. Et.al, A. (2016). White Blood-measuring the lifeliness of the Sin Sze Shi Ya temple. Kuala Lumpur.

6. Guo, Q. (2000). Tile and Brick Making in China: a Study of the Yingzao Fashi. Construction History, $16,3-11$.

7. He, X. (1990). The Source of Feng Shui. Nanjing, Southeast University Press [in Chinese].

8. Jinpeng, D. (2009). A Typological Study of the Palace Buildings at Zhouyuan and Related Issues, 100710, 164-171.

9. kerajaan Malaysia. National Heritage Department of Malaysia (2006). Malaysia. Retrieved from http://www.heritage.gov.my/

10. Lip, E. (1995). Feng shui: Environments of power: A study of Chinese architecture. John Wiley \& Son Ltd.

11. Su, Y. M., \& Tsai, Y. P. (2013). Ecological aesthetic of wind environment about the circular earth building in Fujian,China. Applied Mechanics and Materials (Vol. 368-370). http://doi.org/10.4028/www.scientific.net/AMM.368-370.624

\section{Figures}
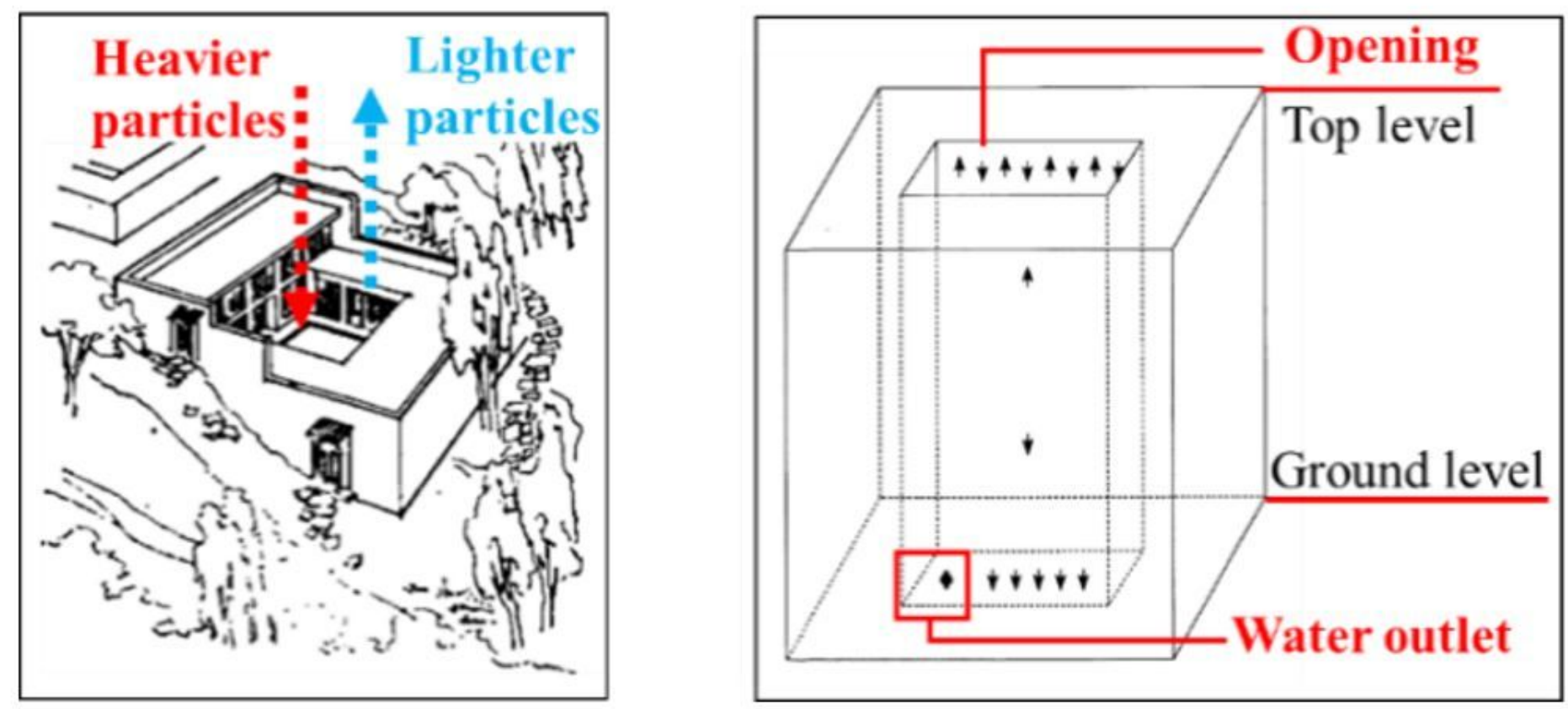

Figure 1

The schematic air ventilation for the courtyard in a quadrangle building. Source: Chen, Feng, \& Wang (1997), rearranged by author 2018 . 

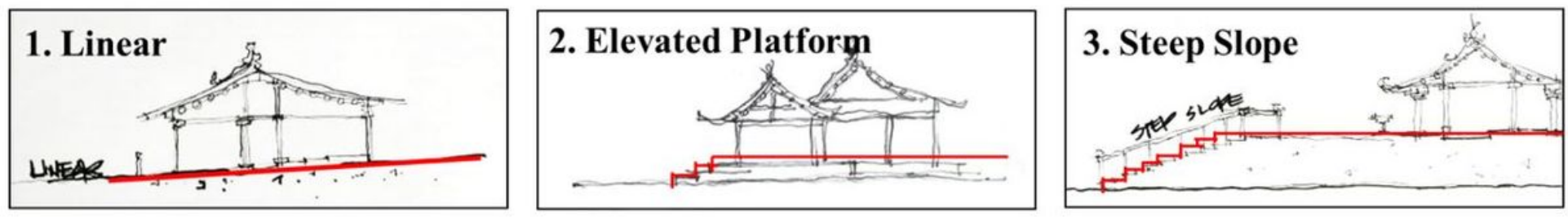

Figure 2

Three categories of model for earth level. Source: Author, (2018)

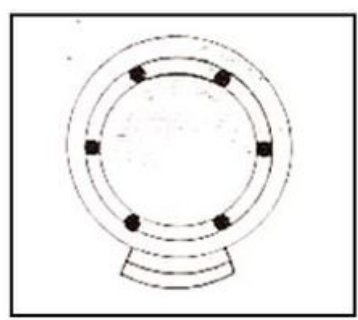

1. Round

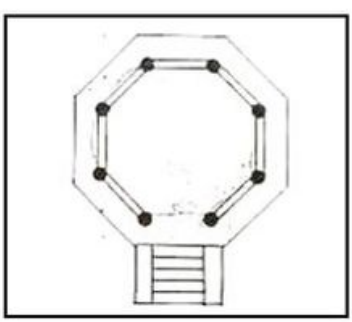

2. Octagonal

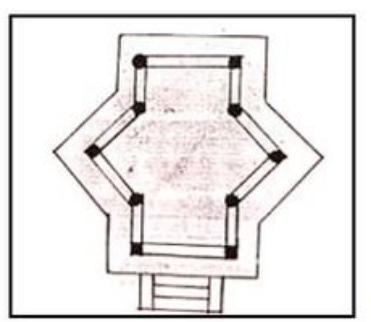

3. Geometry

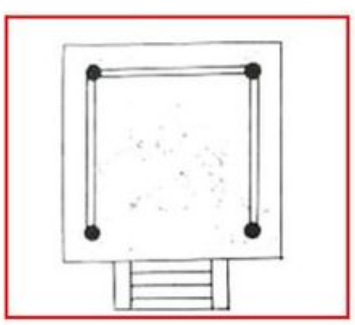

4. Square

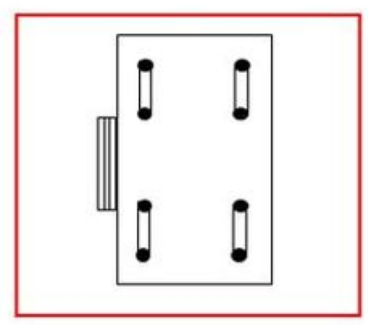

5. Rectangular

\section{Figure 3}

Building models for Taoist Chinese Temples. Only the last two models (highlighted using red lines) are found in Malaysia. Source: Evelyn (1995), rearranged by author (2018).
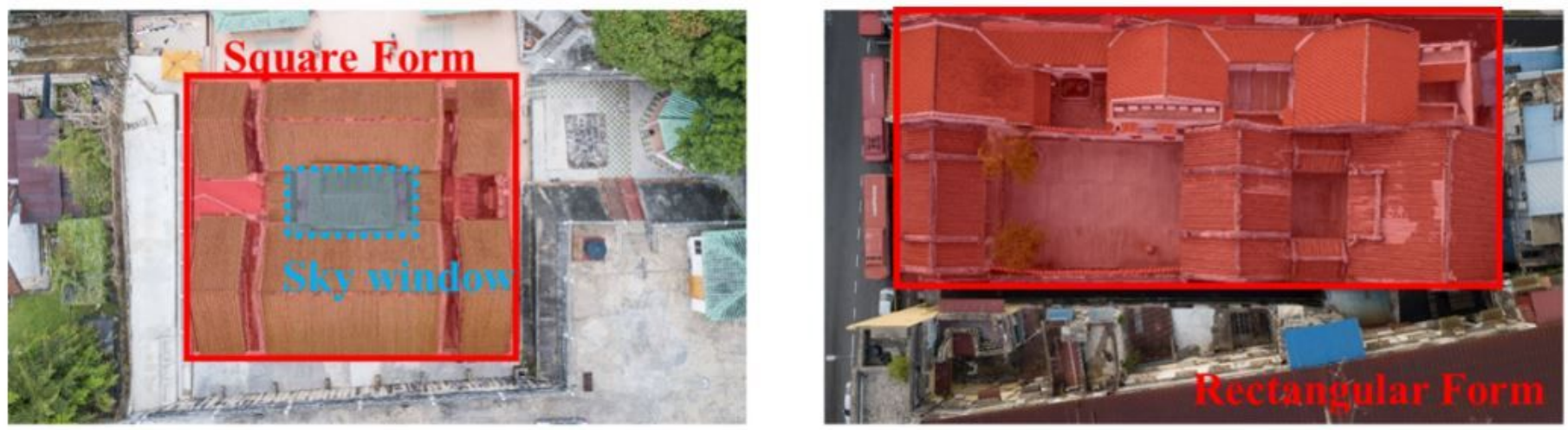

Figure 4

Square and Rectangular shapes, typical models of Chinese Taoist Temples in Malaysia. Source: Author (2018) 

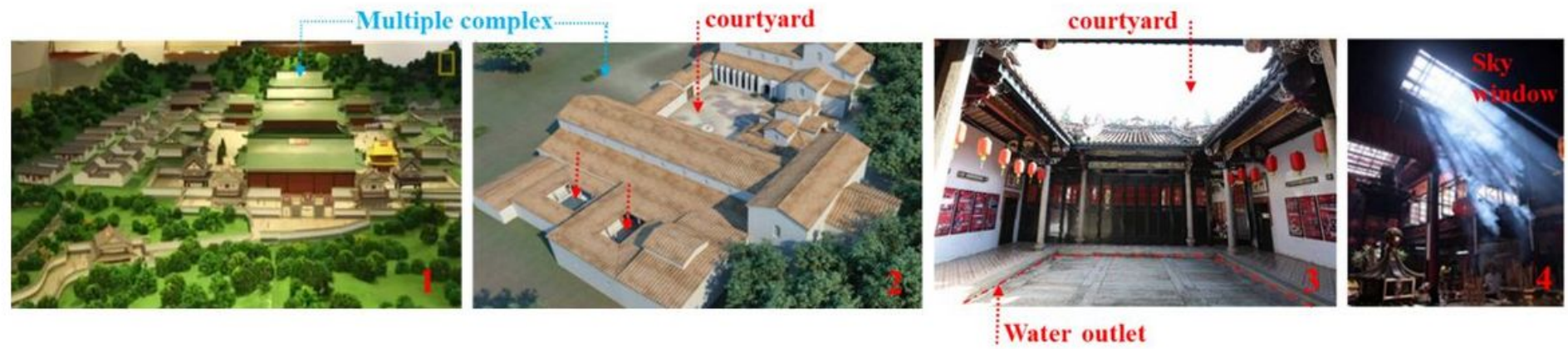

Water outlet

\section{Figure 5}

1. The largest Taoist Temple, the Great Shangqing Palace in Yingtan, Song Dynasty (960-1279), remodelling. Source (Liangyu, 2018) 2. Egara, a former cathedral. Episcopium's patio, early 6th c. Source (Boto Varela, 2017) 3. Teochew Association, Pulau Pinang. Source: Author (2018). Xian Shi Temple KL. (et al. A, 2016)

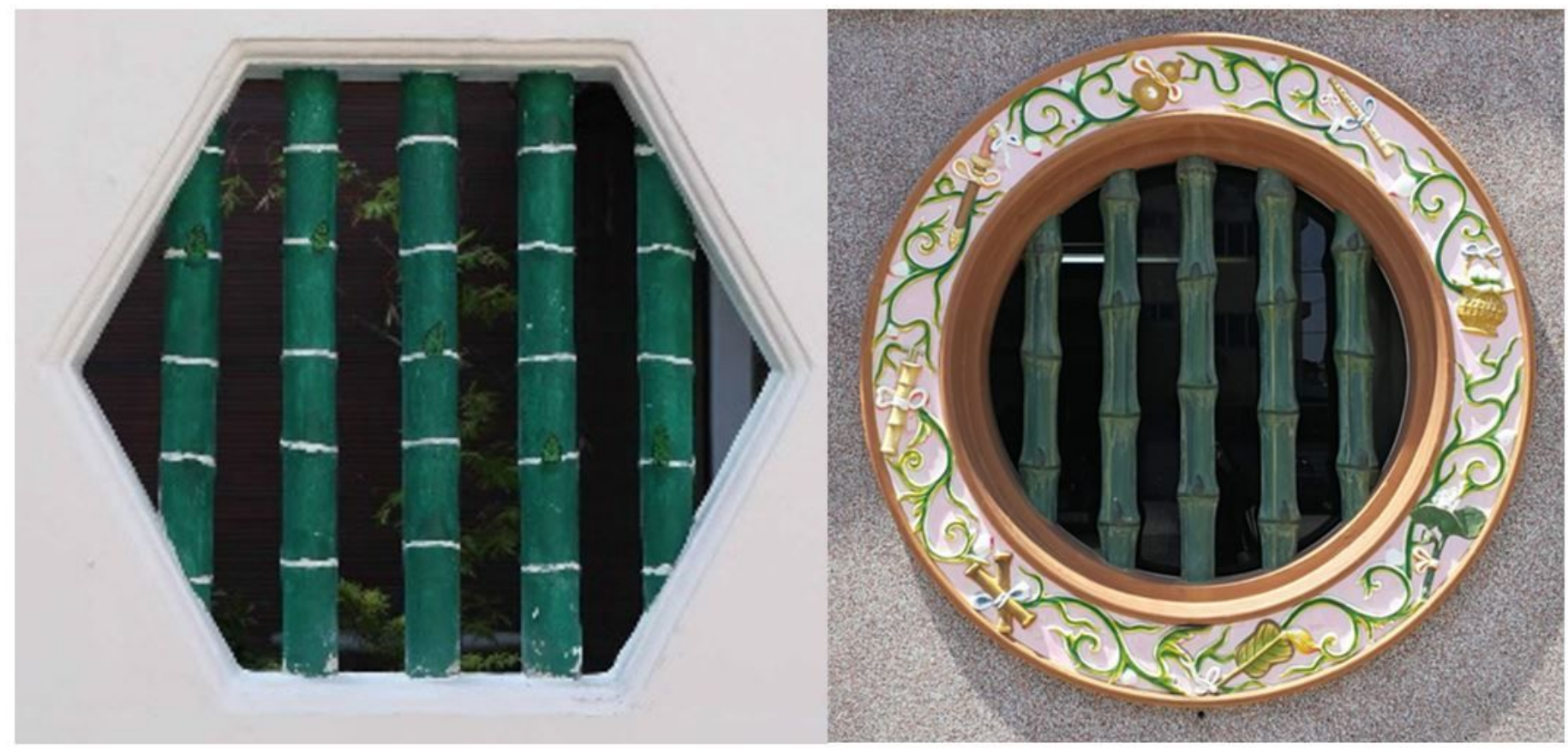

Figure 6

Windows solely served as decorative elements. Source: Author (2018). 